\title{
Matsulu: A community in developmental fermentation and fusion
}

\author{
JOHAN VISSER AND RIAN TERBLANCHE*
}

\begin{abstract}
Since 2004, the Drama Department (University of Pretoria) has engaged in the development and execution of Theatre-for-Development projects in accordance with the mission statement of the Endangered Wildlife Trust (EWT), as well as the White Paper on Integrated Pollution and Waste Management for South Africa (1998) - shifting governmental approach to this sensitive socio-economical issue from cure to prevention - to interrogate issues concerning the environment, sustainable use of resources and subsequently: conservation, within developing urban and rural communities. Theatrefor-Development (TFD) utilizes theatre to disseminate developmental messages.
\end{abstract}

This paper should be seen as not so much as a report of an end result, but as research in progress. Continued projects addressing the issues of conservation, the environment, development and sustainability will in future lead to more definite reporting on results. The paper investigates the ability of TFD to affect changes of behaviour and encourage personal agency and empowerment in community members concerning waste management and the sustainable use of resources within a developing rural society.

It will not claim to be definitive; results and conclusions can not be generalized.

Keywords: Theatre for development (TFD), Endangered Wildlife Trust (EWT), Matsulu, Kruger National Park (KNP), Young Minds Drama Group (YMDG), community development, waste management, sustainable development, HIV/AIDS, poverty.

\section{Introduction}

Conservation, bio-diversity, sustainability together with concepts like eco-friendly and eco-driven development have become major focal points throughout the world during the last decade. South Africa has always been in the spotlight, and leading the way, as far as wildlife management and conservation was concerned. Since 1994, however priorities have shifted to incorporating the peoples of our 'Rainbow Nation' with the idealistic goals of nature conservation.

In September 2003, South Africa hosted (like it will be doing again in 2006) the International Union for the Conservation of Nature IUCN's

* Drama Department, University of Pretoria.

TD: The Journal for Transdisciplinary Research in Southern Africa, Vol. 2 no. 2, December 2006, pp. 391-408. 
World Parks Congress with the theme (in 2003) 'Benefits beyond Boundaries', highlighting the realisation that conservation areas cannot survive as pockets of nature protection in isolation from the people who surround them.

At the time the South African icon, Nelson Mandela, as patron of the congress, stated with his characteristic to-the-point candour: 'To treasure and retain the rich biodiversity of Africa we must ensure that national parks are transformed ... we need to break with traditional thinking, to catalyse a new vision and to join hands in new partnerships' (Borchert, 2003:36).

The most notorious of these parks is, without doubt, the Kruger National Park. Despite people coming and going, regimes rising and falling, Kruger keeps shining like the great conservation diamond it is.

Shortly after 1916, a newly appointed commission was so taken by the beauty of the Sabi Reserve that they determined that the 'uselessness of having this superb reserve merely for the preservation of the fauna' should make way 'for a great national park where the natural and prehistoric conditions of our country can be preserved for all time' (Borchert, 2003:34).

When, a decade later, the National Parks Act No. 56 of 1926 was ratified by the then all-male, all-white parliament, it established the Kruger National Park and made provision for the setting up of other such parks.

The now much larger Kruger Park remains the flagship national park of South Africa and it is quite rightfully regarded as one of the great conservation areas of the world. Quoting Peter Borchert, (2003:34) again:

It is an internationally recognized icon of conservation and few would visit southern Africa with an itinerary that did not include this magnificent reserve.

All along the borders of Kruger, there exist communities (mostly rural, but also semi-urban) anxiously awaiting exactly this transformation and the so-called benefits from beyond their boundaries. This paper will deal with (among other developing rural and urban communities) new partnerships with one of these communities, Matsulu.

In order to imagine some of the problems dealt with by the involved parties, try to visualise the following two scenarios:

It is Friday afternoon 4:30 in Matsulu. Municipal workers responsible for waste removal from Matsulu $\mathrm{C}$ have just filled their truck with refuge. The nearest dumping site is in Nelspruit, 40 minutes away they will only be back home long after nightfall. They agree to secretly dump their load in the bushes on the banks of the Crocodile River, 
close to Matsulu B. Their load also contains rejected meat from the local abattoir. ${ }^{1}$

Saturday morning: children from Matsulu B play on the banks of the river.

They make an exciting discovery - meat (an expensive commodity) delivered on their doorstep. They are unaware of the fact that during the previous night, the local crocodile population also discovered the same 'gift from the gods'. It ends in tragedy. Two toddlers are killed by crocodiles.

\section{Who or what is to blame? Degradation in nature or degradation of culture?}

The second scenario: It is Friday again, the $9^{\text {th }}$ of September 2005. At the community hall, on top of the hill in Matsulu, scores of excited people arrive for a special event: the launch of a new Theatre for Development (or TFD) performance programme on waste management, which was developed during a ten day interactive workshop between the local performers, the Young Minds Drama Group (or YMDG) and post-graduate students of the University of Pretoria's Drama Department (UP Drama). The guests of honour are welcomed by Kenneth Phiri (founder and manager of the YMDG) - among them the mayor of the Mbombela municipality.

Then participating actors (from both YMDG and UP Drama) burst onto the stage and the assembled community members start cheering ... !

What is the link between these two scenes?

The participants are working on the crossroads between nature and culture, conservation and performance art. This paper will thus endeavour to explore the contribution of the authors' discipline and specific field of interest, being performance art, drama and theatre, to the understanding of humankind at the 'Intersection of Nature and Culture'. $^{2}$

1 The community of Matsulu can be divided into three zone groups: Matsulu A, Matsulu B and Matsulu C. Matsulu A has access to running water but mostly through communal taps. They are the middle-class in the community. Matsulu B is an informal settlement without infrastructure and the majority of the people living there are jobless. Matsulu C's residents bring in the highest incomes in the township and have electricity, running water and weekly refuse removal services.

2 The paper originated and was read at the International conference on Humankind at the intersection of nature and culture, 4-6 September, 2006 held in Berg-en-Dal, Kruger National Park - organised by North-West University Vaal Triangle Campus in partnership with the Kulturwissenschafliches Institut Essen, North-Rhine Westphalia, Germany. 


\section{Background and problem statement}

\section{Conservation and development: the issues involved}

In practice, internationally and in South Africa, the formation of policy, legislation and instruments for environmental management remain techno centric and scientific (Scott, et al, 2001). However, this trend is shifting to a focus on poverty and the environment (Weaver, et al, 1999; Scott and Oelofse, 2001). This shift requires a more critical approach to environmental management, one that considers social, ecological and environmental input and justice.

A shift in discipline may include two 'connective threads' holding together the diverse array of sub-disciplines in conservation: 'the Human-Nature relationship and the 'Society and Space' theme (Cloke, et al., 1999). There may be a third theme explored by this investigation that could be termed as an 'integrated approach' - one in which people, environment and place are integrated (Scott \& Oelofse, 2002).

The mentioned shift seems to have been in place in South Africa for a number of years. The words of the late Peter Mokaba, then minister of Environmental Affairs and Tourism, are still relevant as environmental issues are on the increase and pollution continues at an alarming rate: 'In South Africa', he said:
(W)e realise that we can only guarantee democracy and good governance if we have a sound economic and social framework, and one that is also envi- ronmentally sustainable. We will only survive as a country if we have fair access to, ownership of, and control of our renewable and non-renewable natural recourses. In this we must include black and white people, poor and rich people, males and females ... (Government Digest, 2004:38).

If this could be possible, all people in this country and on this continent would be able to live in spiritual, cultural and physical harmony with their natural surroundings. To try and achieve this, government - according to the Government Digest, August 2004 - produced a model based on sustainable development, which addresses, amongst others:

- Holistic and integrated planning and management

- Participation in environmental governance

- Environmental education and empowerment. ${ }^{3}$

The mentioned holistic approach was strongly highlighted in South Africa's previous minister for environmental affairs and now head of the IUCN, Valli Moosa's address to the G8 heads of state meeting in

3 Others include: Sustainable resource and impact management; Effective institutional framework and legislation; Information management for sustainable development; International cooperation. 
Scotland in 2005. It was aptly named: The Nature of Poverty, and the Wealth of Nature (Moosa, 2005). Moosa states:

Without action from, and concern for, people - especially those most vulnerable to environmental degradation and climate change - nothing can be achieved. Increasing the rights of poor people and their access to natural resources, especially in rural areas, increases their responsibilities and can - with clearly defined laws of tenure, access, ownership and rights - unleash grassroots conservation and entrepreneurship on an unprecedented scale (Moosa, 2005).

He comes to the conclusion that:

There is a common misconception that to invest in conservation is somehow contrary to investing in people's livelihoods. However the idea that you need to get rich first and then worry about your environment is not only untrue, it is dangerous. ${ }^{4}$

Wise words indeed. But can a rural community, like Matsulu or Bushbuckridge - both bordering on the Kruger Park - really benefit from investing in conservation in its broadest sense?

The answer seems to be a resounding: Yes!

Simply giving jobs to people in rural areas is not enough. Conservation success depends on a sense of ownership, enabling communities to be meaningful stakeholders, creating incentives to encourage them to protect and nurture the environment. Communities must be engaged in the decision-making process regarding all elements of tourism and utilisation of natural resources (Colman, 2003:43). More than alleviation of poverty, community involvement means equipping members with life skills.

James Blignaut - well known economist - agrees with the notion that conservation offers a viable alternative land-use option to subsistence agriculture on degraded communal land. He argues for a national system that will compensate rural communities for what is potentially their greatest asset - ecosystem goods and services (Bezuidenhout, 2004:8).

Blignaut bases his view on a study in which he compared the total economic value of ecosystem goods and services provided by the pristine Rooibos Bushveld area of the Kruger Park with that of the neighbouring, poverty-stricken and degraded Bushbuckridge area. ${ }^{5} \mathrm{He}$

4 Valli Moosa is President of the World Conservation Union (IUCN) and former South African Minister for Environmental Affairs and Tourism. He was a key negotiator for the African National Congress during the drafting of South Africa's new constitution, hosted the World Summit on Sustainable Development in 2002 and was a Government Minister for 10 years until 2004.

5 Bushbuckridge enjoys the same climate, and once had the same vegetation and animal life as the Rooibos zone of the KNP.

TD, 2(2), December 2006, pp. 391-408. 
found that if the land-use practice of Bushbuckridge would change from subsistence agriculture to private conservation and tourism, allowing sustainable resource harvesting in the area, the community could see a fourfold increase in income (from R1 450,70 per hectare per annum to potentially an astonishing R5 834,70). ${ }^{6}$

We mention tourism because there is already a great number of success stories concerning this in South Africa - including some from the regions and communities involved in this study.

Ecotourism can be traced back to the 1960's and 1970's when many environmental issues began to surface globally. At the time, environmentalism was championed by a few dedicated individuals and organisations with the purpose of addressing waste, over-development, poverty, control and self-sufficiency for communities.

Development was a key concern, as it is today, because relatively few were benefiting from development projects at the expense of many (Fennel, 2003:3). Until tourism provides the socio-economic benefits so sorely needed by rural communities, those communities will continue to use resources unsustainably.

Tourism, whether eco- or cultural tourism, is widely perceived as an industry with the potential to provide communities with job opportunities, income and economic diversity. It is perceived as a generator of tangible benefits to previously disadvantaged communities as well as a key role player in the process of integrating conservation and development (Kibrige, 2003:23).

A Wilderness Safaris statement reads:

\begin{abstract}
One of the successful developments is the concession to 24000 hectares in the far north of the Kruger Park - around the Pafuri area, where the park borders Zimbabwe and Mozambique. The Makuleke community has reclaimed the title deed to the area and entered into a lucrative business venture with Wilderness Safaris. 'These developments will show how communities' commercial interests in utilising protected resources can become profitable and sustainable without being destructive to wildlife (Colman, 2003:44).
\end{abstract}

Other examples come from the Maputo Development Corridor. In this area the CARE programme (Communal Areas and Rural Empowerment), under the auspices of the Mpumalanga Parks Board has identified, and in several cases already developed and established, ecologically sustainable, socially acceptable and financially viable initiatives on community-owned land in rural areas (http:// www.transport.gov.za/library/docs/corrids4.html).

6 Prof James Blignaut - of the University of Pretoria's department of economics - is a well-known economist and shared his findings with Roelof Bezuidenhout. 
To name but a few in close vicinity to Matsulu:

- The Matsulu / N4 Informal Market and business tourism development including a business centre, restaurant, accommodation facilities and other tourism attractions

- The Mthethomusha Game Reserve for ecotourism. The facilities are designed to accommodate between 100 and 150 people, but will at times be able to carry 500 or more people

- The Lomshiyo project - a day visitor facility for the Matsulu community, adjoining the Mthethomusha Community Game Reserve on the Kruger Park boundary. ${ }^{7}$

Benefits from successful environmental partnerships can thus be improved effectiveness, increased efficiency, enhanced equity, effective fulfillment of missions, and improved environmental quality.

\section{Performance practice as educational tool: addressing the issues}

Why do we argue that performance practice is such a powerful and dynamic tool for change? Any conscious attempt to influence behaviour or attitude must engage with culture. Development workers often expect communities to consider new ideas and practices radically different from their own cultural practices, beliefs and knowledge. Theatre for Development - or TFD - and I use this as an umbrella term, should and can exist, as a lubricant, at the interface between social circumstances and development activities. It takes a dialogical form that ensures mutual listening, learning and communication. It is therefore no coincidence that TFD practitioners no longer refer to 'target audiences' or 'target communities', but now prefer the term 'partners' because of the participatory nature of TFD as communications tool (Mavrocordatos, 2005:2).

The reason why we choose to refer to TFD as an umbrella term is because of the astounding number of buzz-words currently doing the rounds in the industry as well as in intellectual and academic circles. Ideas, terms and notions like:

Educational Theatre - including both TIE (Theatre in Education) \& DIE (Drama in Education)

Theatre for Intervention

Theatre for Development

Community Theatre

7 More on these proposed developments available in: Maputo Development Corridor, Section 4: Tourism (http://www.transport.gov.za/library/docs/corrids4.html).

TD, 2(2), December 2006, pp. 391-408. 
Theatre for the Oppressed

Interactive Theatre

Advocacy Theatre, to name but a few.

This may seem confusing, but all of these styles, forms or manifestations of theatre, boil down to more or less the same thing: they are all tools, and a means, by which to empower individuals and groups to take ownership and possession of the possibilities of changing themselves and their environment.

At the heart of this lies the dual meaning of the word 'act' - to perform and to take action. It is fundamental to Theatre for Development that anyone can act and that theatrical performance should not be for professionals only. In its most archaic sense, theatre is the capacity possessed by humans to observe themselves in action. Humans are capable of seeing themselves in the act of seeing, of thinking their emotions, of being moved by their thoughts. They can see themselves here and imagine themselves there; they can see themselves today and imagine themselves tomorrow (Boal, 1985).

Humans are able to identify (themselves and others) and not merely recognize. To identify is to be able to recognize within the same repetitive context but also to extrapolate to other contexts. This is theatre the art of looking at ourselves. In this usage of theatre, all human beings are Actors (they act!) and Spectators (they observe!). They are Spect-Actors. Theatre is thus a form of knowledge; it should and can be a means of transforming society; of changing society. Theatre can help us build our future, rather than just wait for it.

To quote Alex Mavrocordatos:

(T)he first step to development is a change of attitude, both individual and collective - and in that order - from declared helplessness to empowerment.

This is culture in action, and theatre is a cultural tool (2004:3).

The issue of empowerment sits on the bottom line of the (community) development process. Since TFD plays or programmes are usually created spontaneously through improvisation and a workshop process with actors from the specific community, each individual performer not only owns the play's content but the form as well. TFD almost works on the principle of 'home movies' (Mavrocordatos, 2004:9). You are excited to see your brother or sister on the stage, especially if they are exploring problems and interrogating issues that you share.

Other advantages of TFD as communication tool include its ability to break through language and cultural barriers:

- Theatre does not require literacy skills or clever speaking to be effective. 
- Theatre communicates with the whole person - not just with our thinking and reason. It appeals to our emotions, passions and prejudices. It can challenge us to face up to aspects of our lives that we try to ignore.

- It is an entertaining way of sharing information. Adults, like children, learn best when they are interested.

- Theatre does not only use words. It also communicates effectively using mime, images, movement and dance (Prentki \& Lacey, 2005:1).

Furthermore, this style of performance is not a new concept in developing countries and communities. It builds upon the culture and traditions such as traveling theatre, story telling, puppet shows, sociodramas, mimes songs, dance and riddles. For generations, rural populations have relied on these traditional forms of communication to share knowledge, exchange information and to provide entertainment. In situations where profound distrust, fear and anger exist, theatre is a useful medium to bring people together to share stories and trigger emotional responses. The model of using participatory learning methods to explore a group's main concerns and then creating a play in order to debate the issues can be used in many situations. Theatre is a liberating and unifying experience as well as being fun. Follow-up is essential, however, in order to turn the community's reflection into action (Scott-Danter, 1999:4).

\section{UP Drama: getting involved}

At the University of Pretoria's Drama Department, the Drama and/or Theatre for Intervention approach is an eclectic mixture of drama and theatre techniques stemming from the premises, philosophies, strategies and techniques of educational drama or theatre, theatre for development, theatre of the oppressed, community theatre and playback drama or theatre. All of these approaches, in various ways, promote holism, personal empowerment and transformation, social responsibility, advocacy and agency. The focus here is not on creating theatre products or to train performers, but to use drama and theatre as a learning medium. ${ }^{8}$

As part of their curriculum in various courses concerning Theatre: Edutainment and Development, undergraduate as well as post-graduate students at the Drama Department partake in the development and performance of various projects in the field of Theatre for Development or Intervention or Empowerment. These projects serve the

8 Thank you to Dr Marie-Heleen Coetzee for this insight from her Khulisa/UP Drama project proposal, 2005.

TD, 2(2), December 2006, pp. 391-408. 
purpose of informing, uplifting and empowering the specific target group and / or community towards which it is aimed.

Previous projects addressed - among others - the effects of drug abuse on teenagers and caring for the elderly. More recent programmes included: Water wise with Captain Manzi, a project concerned with sustainable use of water resources in urban communities to the north of the (then) Pretoria metropolitan area. This may have been one small step for UP Drama, but it proved to be a giant leap forward for most of the individuals, groups, institutions and communities involved. Since 2004, contact has been established, and a working relationship developed UP Drama and the Conservation Leadership Group (CLG), of the Endangered Wildlife Trust (EWT), to tackle issues concerning the environment, sustainable use of resources and subsequently: conservation. In collaboration with ResourceAfrica, a similar partnership was set up with the Pfukani Theatre Group working in the - already mentioned - Bushbuckridge area.

\section{The EWT: establishing a partnership}

Strategies were developed in accordance with the mission statement of the EWT, namely: The Endangered Wildlife Trust conserves endangered species and ecosystems in Southern Africa by:

- Initiating and funding research and conservation action programmes;

- Preventing species extinction and maintaining biodiversity;

- Supporting sustainable natural management;

- Communicating the principles of sustainable living by education and awareness programmes to the broadest possible constituency.

For the benefit of the people in the region; the goal of the Conservation Leadership Group is: To build capacity in and mobilise aspiring conservationists, enabling them to represent themselves, their communities and the EWT in which ever walk of conservation they choose. After discussion of the mission, vision, activities and specific needs of the CLG with Andre van Zyl, the following strategies were proposed for ongoing projects, starting in 2004: Developing different Theatre for Development programmes to endorse the CLG's Eco-Warrior project - to be performed at schools in Gauteng townships - tying into the Eco-Warrior curriculum and addressing issues concerning, sustainable use of water resources, waste management and pollution, sustainable use of energy resources and finally environmental responsibility.

This project would also involve actors from the CLG's Young Minds Drama Group - working within the Matsulu community in Mpumalanga - in the development and performance of the above mentioned 
programmes. The actors would be utilised not only in the creative development of the various programmes, but also in the implementation thereof. This involvement would also serve the purpose of training and facilitating the participants to employ the same strategies within their own drama group and community.

\section{Matsulu and the Young Minds drama group}

\section{Problem statement concerning waste management in Matsulu}

The quality of the environment continues to decline in many parts of the world. The study of human impact on the environment is not a new one, but resolving problems surrounding this issue globally becomes more pressing almost day by day. The Contemporary Perspectives on Developing Societies series (edited by John Mukum Mbako and Mwangi S. Kimenyi) published a whole volume of research essays in 2003 interrogating this problem: Human Impact on Environment and sustainable Development in Africa (Darkoh, M. \& Rwomire, A. 2003).

This ground breaking study comes to the conclusion that important activities of humans such as industrialisation, technical development, urbanisation and agriculture are increasingly posing a threat not only to the quality of the physical environment but also human health and socio-economic well-being. One life-threatening result of the by-products of development - including waste, pollution and poor sanitation and other infrastructures - is the re-emergence of cholera in South Africa three years ago. The disease has since infected 14000 and killed 250 (Taylor, 2004).

This seems to be exactly the state of affairs in Matsulu. Occurrences of diseases related to waste and pollution are becoming more and more frequent within the community. Apart from the death of the children mentioned in the introduction, the following incidents have been recorded in local and national newspapers since 2003:

- 2003 Community standpipes supplying Matsulu with water did not work for over three months, so people had to walk and drive up to $5 \mathrm{~km}$ to collect water from the polluted Crocodile river (Taylor, 2004).

- 2004 In March a law firm was hired to probe the death of at least eight rural children in a suspected water poisoning scandal. The eight children, all toddlers, died in a cholera outbreak that hospitalised scores of Matsulu residents after the only water treatment plant for the township broke down. Residents were only warned that their drinking water was contaminated by bacteria such as E.coli after local doctors, who treated up to 50 new cases per day, raised the alarm. 
- The Mbombela municipality, in Mpumalanga's capital Nelspruit, initially denied culpability and dismissed public outrage as 'exaggerated' (Mhlabane \& Arenstein, 2004).

- 2004 A few months later, Martha Moyane lost her 14-month-old baby boy, Lindokuhle Jozini, to gastroenteritis and chronic diarrhea, after using contaminated tap water that was fed to Matsulu. 'Dirty water came out of our taps, but no-one bothered to warn us for almost a week that the water had E.coli in it. In fact, the politicians first tried to deny that there was a problem, before suddenly warning us not to drink anything without boiling it. By then it was too late,' said Moyane (http://www.lowveldinfo.com).

- 2005 In July, 2 months before a field trip and workshop week by postgraduate students of UP Drama with the Young Minds Drama Group to create a TFD performance on waste management, another article titled: 'River of Death', appeared in VOICE, the local newspaper. After an investigation by three concerned teachers (several learners and other residents in Matsulu fell ill), once again several plastic bags containing the carcasses of slaughtered animals were discovered in the river. Further investigation led to a dumping site where used motor oil, paint and other toxic materials were dumped on the river banks and oozing into the water (Mbuli, 2005).

Matsulu, surely, is under serious threat because of lack of infrastructure, ignorance and mismanagement of waste and pollution.

André van Zyl (manager of the Conservation Leadership Group of the EWT) conducted an in-depth study to ascertain the extent of the problem and to try and identify possible solutions (Van Zyl, 2004). This research eventually led to the collaboration between UP Drama, the EWT and the YMDG in an attempt to bring about community awareness, mind shifts within individuals and a change in perception of the issues of waste and pollution management. Without going into too much detail concerning Van Zyl's research, it may be said that the population-environment interface in Matsulu follows the so-called Ehrlich and Holden Model (Letamo, G. \& Toloto, O. 2003:105).

The model takes the form: $\mathrm{I}=$ PAT.

Where

$$
\begin{aligned}
\mathrm{I}= & \text { Impact on environment } \\
\mathrm{P}= & \text { Population (size, distribution and rate of growth) } \\
\mathrm{A}= & \text { Affluence (per capita consumption, determined by income } \\
& \& \text { lifestyle) } \\
\mathrm{T}= & \text { Technology (level of impact of consumption) }
\end{aligned}
$$

The population is not the only cause of environmental degradation. 
The consumption of materials and energy per person are also important factors. So is the type of technology used to make consumption possible as well as the economic, social and political forces that influence decision-making (Ehrlich et al., 1977:719). In a developing community, like Matsulu, damage to the environment due to waste and pollution takes place because of rapid population growth with high levels of consumption, economic and political negligence with destructive technology having little impact.

There are three main socio-economic groupings in Matsulu. The higher income group resides in Matsulu $\mathrm{C}$, with water and electricity provided and weekly waste removal services. Matsulu A can be described as the middle-class section, water is provided, but mostly by means of communal taps - most households have access to electricity. Matsulu $\mathrm{B}$ can best be described as an informal settlement. There is an almost complete lack of service provision and infrastructure and most of the residents are unemployed. True to expectations, Van Zyl's findings were that different levels of income, social standing, employment and education yielded different patterns of waste management within the community, both from the people's perspective and from that of the Mbombela municipality providing the waste removal service in the area.

Van Zyl (2004:25) believes that in dealing with the issue of waste in Matsulu, the most powerful medium would be in the form of environmental education, targeting three specific audiences:

- The councillors of the Mbombela municipality in order to inform them of environmental initiatives that could be implemented in the community.

- The women and children of the community who are mainly responsible for the disposal of waste - with the woman also concerned with the well being of their households. ${ }^{9}$

- All staff involved in municipal waste management in order to highlight their responsibility as far as the health and well being of the communities they serve, are concerned.

\section{The Young Minds Drama Group}

The Young Minds Drama Group (YMDG) was founded in 1994 by, among others, Mr. Kenneth Phiri, originally with the aim of establishing a culture of theatrical entertainment within their community. They soon afterwards became involved in community empowerment and upliftment through the enormous talent they have for creating

9 This observation by Van Zyl is indicative of current practice, it must be argued that men need to be educated to be co-responsible.

TD, 2(2), December 2006, pp. 391-408. 
energetic, interactive and spontaneous performances in the discipline of TFD. After going into partnership with, and receiving limited funding from, the CLG and the EWT, Kenneth Phiri \& the YMDG has received numerous awards for acting, scripting and performance for programmes dealing with road safety, conservation issues, HIV and AIDS as well as other health related problems within their community.

Says Ed Farrell in the CLG's annual report (2006):

If we had one wish ... it would be for the YMDG's rehearsal facility to be completed and for us to be in a position to introduce a bursary scheme for meritorious YMDG performers to study drama at the University of Pretoria. It has proven rather difficult for a conservation NGO to do fundraising in the performing arts arena, but if this is the challenge, the CLG will rise to the occasion, because the YMDG is too talented and the work they are doing too valuable not to give it our all.

\section{The partnership and the learning experience}

Described as a particular highlight in 2004 by the EWT, was the establishing of the partnership between UP Drama, the CLG and the YMDG in order to join creative forces to present the so-called EcoWarrior message to young audiences in exiting and novel ways (Farrell, 2006). Based on their Eco-Warrior curriculum, two plays / programmes were developed and performed in Soweto, Tembisa and Bosmond. This involved four actors from the YMDG in the development and performance of the programmes. The actors were utilised not only in the creative development of the various programmes, but also in the implementation thereof. This involvement also served the purpose of training and facilitating the participants to employ the same strategies within their own drama group and community.

During the week of 17-21 May, 2004, Water wise with the Water Warriors and Waste wise with the Waste Warriors were performed at ten schools in urban Gauteng communities to an estimated 5650 learners. For May 2005, the same recipe was followed with the creation of the performance programme: My Footprint on the Environment, this time involving four other YMDG actors. With seven performances of this play, more than 4900 learners were reached.

During August and September 2005, field trips and the interactive workshop between the YMDG and Honores-students, mentioned in the introduction, led to the community launch of YMDG's ownTFD programme on conservation and waste management. Over a period of three months, performances of this programme were given in some twenty primary and secondary schools in and around Matsulu (Mpumalanga), reaching over 10000 learners. The partnership turned out to be a 'four-way' learning experience. Not only the learners and 
teachers at the various schools, but also the staff members and students of UP Drama, the actors of the YMDG as well as the EWT and their Eco-Warriors working in the schools all gained valuable knowledge and experience from the project to be put to good use in future projects.

Valuable experience was obtained and lessons learned by the different groups involved. The workshop and rehearsal process exposed both groups of actors (Drama Students and Young Minds Drama Group) to acting styles and disciplines they have not previously experienced: the 'community theatre' style of acting practiced by the YMDG enriched and enhanced the more formalised 'educational theatre' style of the drama students, and vice versa.

In reaction to the launch of the YMDG's performance, Ms Pontso Mabelane - representing the MEC for culture, sports and recreation, said that she was impressed:

My department has everything in place to help such groups to grow and represent the country not only locally, but abroad. Please come forward with a business plan so that we can find out what assistance you need (Nyalanga, 2005).

Kenneth Phiri, founder of the group, stated:

We have been working very closely with the lectures and students of this institution (UP Drama). They also train our group to produce the best performances ever (Nyalanga, 2005).

Feedback from the members of the YMDG can be summed up in the words of Margaret Phiri - cousin of Kenneth:

We were received by the warm and welcoming hands of the teachers, students and institution itself, we couldn't be much more at home. It felt like we belonged with them. The rehearsals were tough; we were working very hard because we were playing the lead roles, with classes in between on movement, theatre for development, choreography and voice. They tried to equip us with a lot of information in a short time. They learned from us and we did from them. The performances were great. Thank you for the opportunity, I hope the friendship between the EWT, the Varsity and the YMDG doesn't end here (Farrell, 2006).

\section{Objectives and outcomes}

- Creating awareness of the problems and issues surrounding sustainable development and use of resources within specific urban and rural communities as envisioned and set out in the "White Paper on Integrated Pollution and Waste Management' of the Departments of Environmental Affairs and Tourism \& Water Affairs and Forestry. (Refer specifically to section 4: Approaches to Integrated Pollution and Waste Management, subsection 4.1: Shift to Prevention.) 
- Developing a sense of awareness, pride and responsibility within the learners and members of specific communities as to the value and advantages of taking responsibilty for their environment, thereby empowering them to develop their own strategies of sustainable development (in the 2005 programmes this was achieved by pointing out strategic planning for the 2010 World Soccer Cup Tournament).

- Setting up continued involvement with the specific target communities by means of information hand-outs, brochures and follow up workshops.

- Introducing the idea of turning waste into usable resources, involving existing recycling establishments like:

o Enviro Plastics Recoveries

o Glass Recycling Association (Enviroglass)

o Mondi Recycling

o Collect-A-Can

- Future involvement in CLG projects like the Makuleke Training Project, the Conservation Training Programme, the Eco-Warrior Programme, the Young Minds Drama Group and others.

- Establishing an interactive relationship between the students of the Drama Department and the participants in projects run by the EWT in rural and other communities.

- Setting up a framework for future co-operation between the institutions involved, for example:

o Developing short courses within the framework of Theatre for Development and other related disciplines.

o Establishing funding for full time studies at the University of Pretoria for deserving candidates from CLG projects.

o Empowering the various role players participating in this project to enable them to set up and create their own Theatre for Development projects within their communities.

\section{Conclusion}

It may be too soon to determine the results of the work of UP Drama and the YMDG within the Matsulu community, but preliminary findings by means of various questionnaires, interviews and discussions indicate that there is a significant shift within the respondents in recognizing individual, family and communal responsibility in waste management. TFD is a way of using theatre to stimulate debate, getting people to question issues in a public forum. It asks questions without dictating the answers - it is never didactic to its audience, it involves a process of learning together rather than one-way teaching; it assumes that there is as much likelihood of the audience knowing the answers as the performers. TFD can not provide the community with answers. It can, however, provide them with the opportunities to experience possible answers. 


\section{References}

African Eye News Service, 2004: Mourning Mothers Want to Sue. Published on: http://ww.lowveldinfo.com/news/showstory. asp?story $=5920$.

Bezuidenhout, R., 2004: Poverty versus conservation, in Farmer's Weekly, 2 April, 2004, 8.

Boal, A., 1985: Games for actors and non-actors. Intro. \& Transl.: Adrian Jackson. London and New York: Routledge.

Borchert, P., 2003: From the past ... into the future: South Africa's National Parks, in Africa Geographic (11) 8, September 2003, Black Eagle Publishing, Cape Town, 6; 28-45.

Cloke, P., Crang, P. \& Goodwin, M., 1999: Introducing human geographies. Arnold, London.

Colman, M. 2003: Communities - the essential ingredient in the conservation pot, in The Journal of Southern African Tourism. June, 2003, 43-46.

Darkoh, M. \& Rwomire, A., 2003: Human Impact on Environment and Sustainable Development in Africa. Ashgate, Burlington, USA.

Darkoh, M. \& Rwomire, A., 2003: Human Impact on Environment and Sustainable Development in Africa. Ashgate.

Farrel, E., 2005: CLG Bulletin. Published on: http://www.ewt.org.za/ workgroups_overview.aspx?group=leadership\&page.html.

Fennell, D.A., 2003: Ecotourism in the South African context, in Africa Insight. (33) 1/2, 3.

Kibrige, R., 2003: The socio-economic impacts of tourism on poor rural communities, in Africa Insight. (33) 1/2, 23.

Maputo Development Corridor, Section 4: Tourism. Published on http:/ /www.transport.gov.za/library/docs/corrids4.html.

Mavrocordatos, A. 2004: Theatre for Development - Cultural Action or Development Utility? Published on: http://www.comminit. com/papers/p_0037.html.

Mbuli, M., 2005: River of Death, in VOICE, issue 92: July 1, 2005.

Mhlabane, J, \& Arenstein, J., 2004-03-24: Independent investigations begin into Mpumalanga water scandal, for African Eye News Service. Published on: http://www.lowveldinfo.

Moosa, V. 2005: The Nature of Poverty, and the Wealth of Nature. Published on www.africageographic.com. 
Nyalunga,S., 2005: New Beginnings for Young Minds, in Voice, issue 113: September 13, 2005.

Prentki, T. \& Lacey, C., 2005: Using theatre in development. Published on: http://www.kit.nl/specials/html/td_theatre_and_ devlopment.asp?specials/html.

Scott, D. \& Oelofse, C., 2001: Social impact assessment as a development tool: principles and practices in a developing context. Proceedings of the annual Conference of the Local Chapter of the International Association of Impact Assessment (IAIA), White River, 7-10 October, 2001, 262-279.

Scott, D. \& Oelofse, C., 2002: Geography and environmental management in South Africa, in South African Geographical Journal (84) $1,38-47$.

Scott, D., 2001: Environmental identity and social transformation: experiences from South Durban. Department of Geography Seminar Series, Cambridge University, 2001.02.05.

Scott-Danter, H., 1999: Theatre for Development: a dynamic tool for change. Published on: http://www.fmreview.org/text/FMR/06/ 07.htm.

Take ownership of non-renewable and renewable resources, Government Digest. August 2004.

Taylor, H., 2004: A thirst for profit. Published on: http://www.unison. org.uk/features/features/0206thirstforprofit.asp.

Van Zyl, A., 2004: Waste and pollution management - the CLG's perspective. Unpublished. 